\title{
New Insights Into Wall Polysaccharide O-Acetylation
}

\author{
Markus Pauly and Vicente Ramírez* \\ Institute for Plant Cell Biology and Biotechnology - Cluster of Excellence on Plant Sciences, Heinrich Heine University \\ Düsseldorf, Düsseldorf, Germany
}

\section{OPEN ACCESS}

Edited by:

Georgia Drakakaki,

University of California, Davis,

United States

Reviewed by:

Yumiko Sakuragi,

University of Copenhagen, Denmark

lan S. Wallace,

University of Nevada, Reno,

United States

Olga A. Zabotina,

lowa State University, United States

*Correspondence: Vicente Ramírez

ramirezg@hhu.de

Specialty section:

This article was submitted to

Plant Cell Biology,

a section of the journal

Frontiers in Plant Science

Received: 30 May 2018

Accepted: 27 July 2018

Published: 21 August 2018

Citation:

Pauly M and Ramírez V (2018) New Insights Into Wall Polysaccharide

O-Acetylation.

Front. Plant Sci. 9:1210.

doi: $10.3389 /$ fpls.2018.01210
The extracellular matrix of plants, algae, bacteria, fungi, and some archaea consist of a semipermeable composite containing polysaccharides. Many of these polysaccharides are $\mathrm{O}$-acetylated imparting important physiochemical properties to the polymers. The position and degree of $\mathrm{O}$-acetylation is genetically determined and varies between organisms, cell types, and developmental stages. Despite the importance of wall polysaccharide $\mathrm{O}$-acetylation, only recently progress has been made to elucidate the molecular mechanism of $\mathrm{O}$-acetylation. In plants, three protein families are involved in the transfer of the acetyl substituents to the various polysaccharides. In other organisms, this mechanism seems to be conserved, although the number of required components varies. In this review, we provide an update on the latest advances on plant polysaccharide $\mathrm{O}$-acetylation and related information from other wall polysaccharide $\mathrm{O}$-acetylating organisms such as bacteria and fungi. The biotechnological impact of understanding wall polysaccharide $\mathrm{O}$-acetylation ranges from the design of novel drugs against human pathogenic bacteria to the development of improved lignocellulosic feedstocks for biofuel production.

Keywords: O-acetylation, cell wall, polysaccharides, biosynthesis, mechanism

\section{PLANT CELL WALL POLYMERS ARE O-ACETYLATED}

The biomass of plants contains considerable amounts of esterified acetate. For example, poplar wood contains $5 \%$ of its weight as acetate (Johnson et al., 2017), while corn stover contains $4.5 \%$ (w/w; Chundawat et al., 2010). Upon processing of the plant biomass the acetate is often released (Selig et al., 2009) not only acidifying the resulting material, but also presenting a potent inhibitor for further downstream microbial fermentation (Helle et al., 2003) such as for the production for biofuels.

The predominant portion of the bound acetate found in plant biomass is present in the cell wall material in the form of $O$-linked acetate on many wall polysaccharides (references below), and to a minor extent on the polyphenol lignin (Ralph, 1996; Del Río et al., 2007). While cellulose, callose, mixed-linkage glucans, and structural glycoproteins are not $O$-acetylated, the dominant matrix polysaccharides including the various pectic polysaccharides and hemicelluloses such as xylan, xyloglucan, and mannans can be $O$-acetylated (Gille and Pauly, 2012). The position and degree of acetylation depends on the wall polymer and can differ not only between plant species, but also cell types, and/or the developmental stage of the plant (Del Río et al., 2007; Obel et al., 2009; Pauly and Keegstra, 2010; Gille and Pauly, 2012; Lourenço et al., 2016). Both the polymer 
glycan-backbone and/or the side-chain sugar moieties can be O-acetylated (Kiefer et al., 1989; Ishii, 1991, 1997; Pauly, 1999; Teleman et al., 2000; Lundqvist et al., 2002; Kabel et al., 2003; O’Neill et al., 2004; Gibeaut et al., 2005; Hoffman et al., 2005; Jia et al., 2005; Hsieh and Harris, 2009; Sengkhamparn et al., 2009). For example, the hemicellulose xyloglucan (XyG) predominantly found in dicot species contains $O$-acetyl moieties on the galactosyl side-chain residues, while in Solanaceous plants and grasses, the glucan-backbone of xyloglucan is $O$-acetylated. In addition, several wall polymers contain sugar-residues that can be mono-/or di-O-acetylated (reviewed in Gille and Pauly, 2012).

\section{POLYSACCHARIDE O-ACETYLATION MECHANISM}

Several lines of evidence suggest that $O$-acetylation of wall polysaccharides takes place as part of the polysaccharide biosynthesis in the Golgi lumen. First, acetylated xyloglucan can be isolated from microsomal preparations suggesting that $\mathrm{O}$-acetylation takes place before the wall polysaccharides are secreted into the apoplast (Obel et al., 2009). Second, pectic polysaccharides can be $O$-acetylated in vitro in isolated plant microsomes (Pauly and Scheller, 2000). Third, all proteins involved in this modification (see below) are predicted to be located in the Golgi membrane with the putative catalytic domains facing the Golgi lumen (Gille et al., 2011b; Lee et al., 2011; Manabe et al., 2011; Yuan et al., 2013; Schultink et al., 2015; Gao et al., 2017). However, it should be noted that the degree and pattern of polysaccharide $O$-acetylation is also determined by apoplastic plant $O$-acetylesterases, presumably post-deposition in the wall (Gou et al., 2012; Orfila et al., 2012; de Souza et al., 2014; Zhang et al., 2017).

The identification of plant mutants affected in the $O$-acetylation of wall polysaccharides has been instrumental in our understanding of the molecular mechanism of polysaccharide $\mathrm{O}$-acetylation. Based on these findings, so far three different protein families are involved in polysaccharide $\mathrm{O}$-acetylation (Figure 1). One of these protein families is the TRICHOME-BIREFRINGENCE-LIKE (TBL) protein family comprising 46 members in the model species Arabidopsis thaliana. Members of the TBL family have been shown to participate in the $O$-acetylation of specific wall polymers. Loss-of-function of the Arabidopsis ALTERED XYLOGLUCAN 4 (AXY4/TBL27) gene results in a complete lack of $O$-acetyl substituents on the hemicellulose XyG without affecting the acetylation status of the other wall polymers (Gille et al., 2011b). Its paralogous gene - AXY4-like $(A X Y 4 L / T B L 22)$ - appears to have the same function but specifically in seeds, indicating that AXY4 and AXY4L are XyG-specific acetyltransferases, although the biochemical activity of both proteins remains to be experimentally demonstrated.

Another well studied example is the Arabidopsis tbl29/eskimo1 mutant that was shown to reduce xylan $O$-acetylation by $46 \%$ in the stem (Xiong et al., 2013). The corresponding TBL29/ESKIMO1 protein was found to catalyze the transfer of $O$-acetyl groups to $\beta$ - $(1 \rightarrow 4)$ xylooligosaccharides in vitro thus confirming its role as a xylan $\mathrm{O}$-acetyltransferase (Urbanowicz et al., 2014). Recently, the xylan $O$-acetyltransferase activities of other TBL proteins and their regiospecificity of xylose 2-Oand/or 3-O-acetylation has been demonstrated in Arabidopsis, rice, and poplar (Zhong et al., 2017, 2018a,b). In summary, in Arabidopsis, 9 TBLs lead to xylan 2-O-, 3-O-monoacetylation or 2,3-di-O-acetylation (Zhong et al., 2017). In rice, $66 \mathrm{TBL}$ genes have been identified (Gao et al., 2017). Among these, 14 TBL proteins show xylan 2-O- and 3-O-acetyltransferase activity (OsXOAT1-14). OsXOAT1-7 are able to complement the defects in xylan $O$-acetylation of the Arabidopsis esk1/tbl29 mutant (Zhong et al., 2018a). In poplar 64 TBLs were identified, 12 of those proteins were shown to $O$-acetylate xylan when heterologously expressed (Zhong et al., 2018b). Other members of the TBL family are thought to be involved in pectin $O$-acetylation such as AtPMR5/AtTBL44, AtTBR, and AtTBL3 (Vogel et al., 2004; Bischoff et al., 2010a) or mannan O-acetylation in the case of AtTBL25/AtTBL26 (Gille et al., 2011a). However, in all of these cases enzymatic activity and specificity remains to be demonstrated.

TRICHOME-BIREFRINGENCE-LIKE proteins contain three characteristic protein signatures (Figure 1) (Bischoff et al., 2010b). A N-terminus transmembrane domain and two plantspecific domains, DUF231 and TBL. The DUF231 is a domain of unknown function containing a conserved $\mathrm{DxxH}$ motif while the TBL motif is characterized by the presence of an esterase GDS motif. The Ser residue from the GDS motif and the Asp and His residues of the $\mathrm{DxxH}$ motif are essential for the function of TBL29/ESK1 as mutations of these residues result in a loss of enzyme activity (Zhong et al., 2017).

A second family of proteins involved in polysaccharide $O$-acetylation is represented by ALTERED XYLOGLUCAN 9 (AXY9; Figure 1). Arabidopsis mutants affected in AXY9 expression show a strong reduction in total wall $O$-acetylation in stems and leaf tissues (Schultink et al., 2015). Interestingly, unlike the large, diversified TBL gene family, $A X Y 9$ seems to be present in the genome of land plants only as a single copy. Contrary to the polysaccharide substrate specificity of TBL proteins, AXY9 seems to be non-specific in polysaccharide $O$-acetylation as the corresponding axy9 mutant plants display reductions in $O$-acetylation of multiple hemicelluloses such as xyloglucan or xylan but not pectin. Due to these unique features, AXY9 has been suggested to be involved in the generation of an intermediate acetyl donor substrate used later by TBL proteins (Schultink et al., 2015). The AXY9 protein contains a N-terminus transmembrane domain and a C-terminus facing the Golgi lumen containing GDS and DxxH motifs (Figure 1) suggesting that it could also be an $\mathrm{O}$-acetyltransferase although if this protein harbors any enzyme activity has yet to be determined.

REDUCED WALL O-ACETYLATION (RWA) is the third group of proteins involved in plant polysaccharide $O$-acetylation (Manabe et al., 2011) (Figure 1). The Arabidopsis genome contains four RWA proteins required for $\mathrm{O}$-acetylation of both pectic and non-pectic polysaccharides including xyloglucan, xylan, and mannan. Quadruple rwa mutant plants exhibit a $63 \%$ reduction in total wall $O$-acetylation (Manabe et al., 2013). Similarly, down-regulation of the four $R W A$ genes found in 


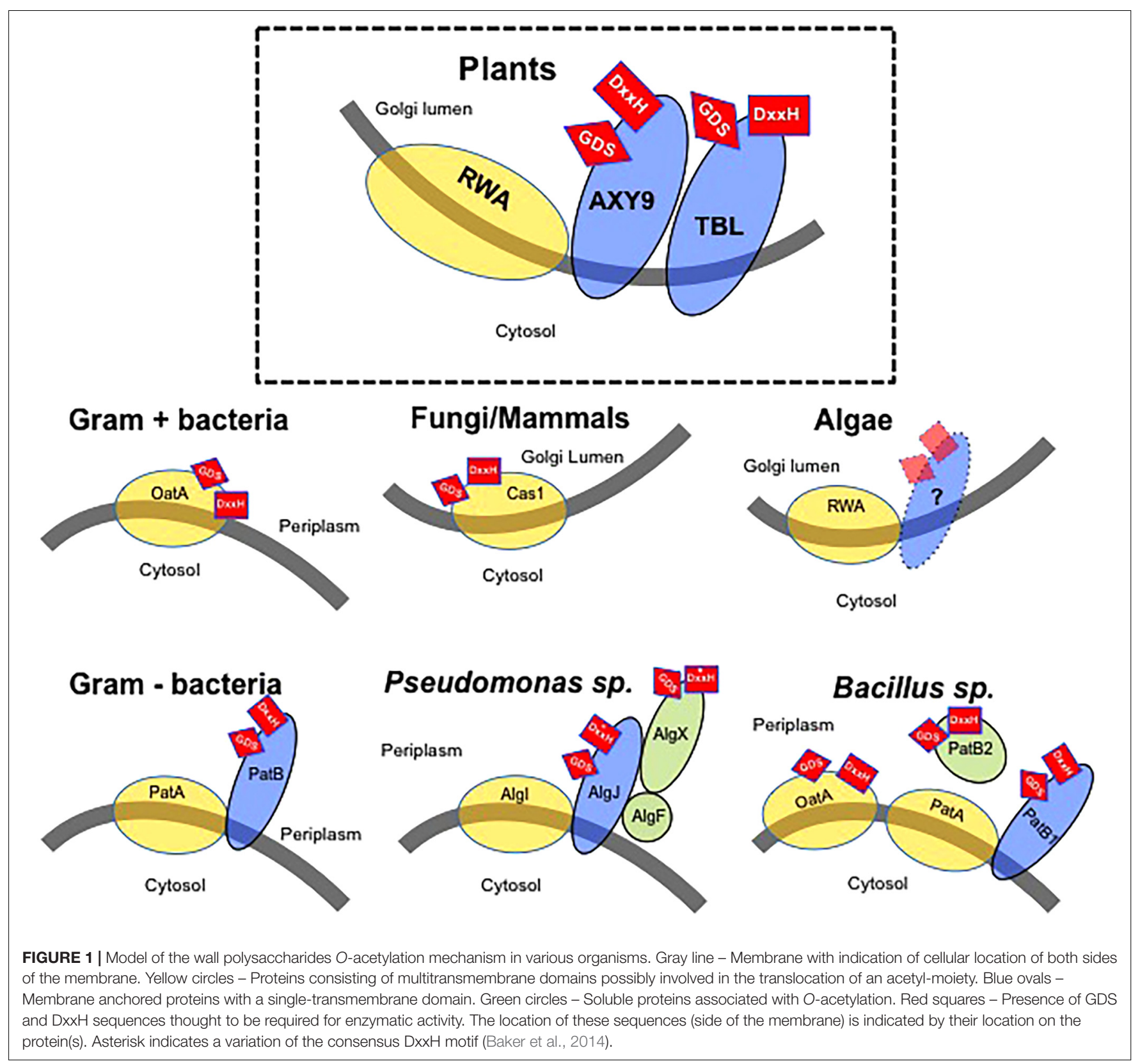

hybrid aspen (Populus tremula $x$ tremuloides) results in reduced wood xylan and xyloglucan $O$-acetylation, suggesting that RWA function is conserved among plant species (Pawar et al., 2017). RWA proteins are characterized by the presence of 10 predicted transmembrane domains (Manabe et al., 2011). In contrast, AXY9 and TBL proteins contain a single transmembrane domain anchoring the protein to the Golgi membrane while the C-terminus of these proteins is oriented toward the Golgi lumen containing the putative catalytic motifs. Despite the lack of amino acid similarity, all these enzymes are predicted to have a short N-terminal cytoplasmic region that has been proposed to act as a signal for retention in the Golgi in the case of other proteins such as glycosyltransferases (Banfield, 2011), although no experimental evidence has been obtained so far for
AXY9 or TBL proteins. Also, microsomal preparations isolated from potato cells incubated with radio-labeled acetyl-CoA are able to incorporate and transfer radioactive acetate to proteins and cell wall polysaccharides suggesting that acetyl-CoA is a donor-substrate for the $O$-acetylation of wall polysaccharides (Pauly and Scheller, 2000). As acetyl-CoA cannot diffuse through membranes and the Golgi is not able to produce it (Oliver et al., 2009), it has been proposed that RWA is responsible for the translocation of acetyl-groups across the membrane in order to supply the substrate to the other two families of $O$-acetyltransferases (AXY9 and the various TBLs). Although no experimental evidence has been reported yet, the existence of intermediary acetyl donor(s) is a likely option (Lee et al., 2011; Manabe et al., 2011, 2013; Schultink et al., 2015). In any case, the 
cytosolic pool of acetyl-CoA is likely the source used by plants for the $O$-acetylation of polysaccharides as it is for alkaloids, anthocyanins, isoprenoids, or phenolics (Fatland et al., 2005; Oliver et al., 2009).

\section{SIMILARITIES WITH OTHER POLYSACCHARIDE O-ACETYLATING ORGANISMS}

All Gram-positive and most Gram-negative bacteria $O$-acetylate extracellular polysaccharides such as their cell wall peptidoglycan (PG) polymer. This heteropolymer is the main component of the bacterial wall, and consists of alternating $N$-acetylglucosaminyl$(\beta-1,4)-N$-acetylmuramoyl residues cross-linked with stem peptides. PG O-acetylation can occur in $20-70 \%$ of the MurNAc residues, depending on the species and growth conditions and provides protection against lytic enzymes such as lysozyme (Moynihan and Clarke, 2011). In the last few years, a great effort has been made to identify and characterize the proteins involved in the $O$-acetylation of PG and other secondary cell wall polysaccharides due to the importance of this modification for the virulence of human pathogens such as Neisseria gonorrhoeae, Bacillus anthracis, or Streptococcus pneumoniae (Moynihan and Clarke, 2010; Moynihan et al., 2014; Sychantha et al., 2017, 2018). One can find surprising similarities of those systems with the polysaccharide $O$-acetylation mechanisms in plants indicating common ancestry.

In Gram-positive bacteria, OatA proteins consist of a $\mathrm{N}$-terminal RWA-like multitransmembrane domain fused to a globular extracytoplasmic C-terminal domain containing a SGNH/GDSL esterase motif with similarity to plant TBL proteins (Figure 1). Hence, Gram-positive bacteria seem to be simultaneously translocating the acetyl groups from a cytoplasmic source and $\mathrm{O}$-acetylating the $\mathrm{N}$-acetylmuramoyl residues in the extracellular PG polysaccharide using a single bimodular protein. Several OatA homologs have been identified and characterized but only recently the crystal structure of the C-terminal domain of OatA has been resolved and point mutations in the DxxH and GDS motifs demonstrated that these amino acids are essential for catalyzing $O$-acetylation of $P G$ in Streptococcus pneumoniae and Staphylococcus aureus (Sychantha et al., 2017). A similar protein combination consisting of a globular $\mathrm{O}$-acetyltransferase domain combined with multiple transmembrane domains is also observed in fungi and mammals. The fungal CnCasip protein is responsible for the $O$-acetylation of capsular glucuronoxylomannans in Cryptococcus neoformans (Janbon et al., 2001) (Figure 1). Although its activity has not been determined experimentally, the human $\mathrm{HsCasD} 1$ protein, showing high similarity and structure to CnCaslp, has been demonstrated to be essential and sufficient for $O$-acetylation of sialic acids, a family of nine-carbon monosaccharides typically found capping the glycan chains attached to cell surface glycoproteins and glycolipids in mammals including humans (Arming et al., 2011; Baumann et al., 2015). Similarly to bacterial OatA, activity assays showed that a $\mathrm{N}$-terminus globular domain of HsCasD1 containing the SGNH/GDSL motif catalyzes the
9-O-acetylation of sialic acids in vitro (Baumann et al., 2015). These results suggest an ancient functional fusion between the multitransmembrane and globular domains in a single protein as a common mechanism to $\mathrm{O}$-acetylate extracellular polysaccharides in Gram-positive bacteria, fungi, and mammals (Janbon et al., 2001; Anantharaman and Aravind, 2010; Baumann et al., 2015).

In Gram-negative bacteria multitransmembrane proteins have also been involved in $\mathrm{O}$-acetylation of extracellular polysaccharides, such as NolL that $\mathrm{O}$-acetylates lipo-chitin oligosaccharides in Rhizobium species, or GumG and GumF involved in the acetylation of the mannose residues of xanthan gum produced by Xanthomonas oryzae (Pacios Bras et al., 2000; Kim et al., 2009). However, the $O$-acetylation machinery of Gram-negative bacteria consists of multiple proteins as has been observed in plants (Figure 1). A multitransmembrane protein might translocate the acetyl moieties from a cytoplasmic source into the periplasm, where one or more plasma membraneanchored proteins containing a SGNH/GDSL motif facing the periplasm might transfer the acetyl-moiety to the polysaccharide (Figure 1). This two-component mechanism involves the coordinated expression of multiple components arranged in operons. A model was originally proposed based on the $O$-acetylation of alginate, a linear exopolysaccharide consisting of 1-4-linked L-mannuronyl and D-glucuronyl residues present in Pseudomonas aeruginosa (Figure 1) (Clarke et al., 2000). In this bacterial species, the multi transmembrane domain protein AlgI has been suggested to play a similar role as OatA or RWA, exporting the acetyl groups from the cytoplasm. The available acetate would then be used by AlgJ and AlgF proteins, both containing a SGNH/GDSL motif. Although AlgJ and AlgF are both required for alginate $O$-acetylation, their precise functions have not been experimentally demonstrated and it has been proposed that they would not transfer acetyl groups directly to alginate. Instead, they would form a complex that could be acting as an intermediary step providing acetyl groups to $\mathrm{AlgX}$, a protein shown to be able to $O$-acetylate the mannuronyl alginate residues in vitro (Baker et al., 2014). According to this model, the intermediate proteins AlgJ and AlgF might be analogous to AXY9 in plants, whereas AlgX would be catalyzing the final step in the $O$-acetylation of alginate, playing a similar role as the TBL protein family in plants. A similar mechanism has been postulated for other Gram-negative bacteria, including N. gonorrhoeae or Campylobacter jejuni (Figure 1) (Weadge et al., 2005; Moynihan and Clarke, 2010; Ha et al., 2016). In these Gram-negative bacteria, several homologs of AlgI (i.e., PatA proteins) are supposed to translocate the acetyl groups through the plasma membrane, whereas PatB proteins catalyze the transfer to the C6 hydroxyl groups of the PG muramoyl residues.

Despite the presence of proteins containing multiple transmembrane domains in both one- and multiple-component polysaccharide $\mathrm{O}$-acetylating systems, proteins such as OatA, RWA2 or AlgI share very limited sequence homology with PatA. For example, SaOatA and NgPatA share only $15.1 \%$ sequence identity and $23.6 \%$ similarity. A similar situation occurs when comparing the $\mathrm{O}$-acetyltransferase domain of plant TBL or 
Gram-positive bacterial OatA proteins with the Gram-negative $\mathrm{AlgX}$ or PatB proteins. For example, there is only $15.4 \%$ identity and $18.3 \%$ similarity between the globular domain of SaOatA and HgPatB (Sychantha et al., 2017). This low degree of sequence similarity suggests different evolutive origins.

Interestingly, some Bacillus species seem to have two independent machineries to $O$-acetylate extracellular polysaccharides (Figure 1). On the one hand, a bimodal OatA homolog has been characterized exhibiting a mechanism as described above, involving the simultaneous translocation of acetyl groups and PG $O$-acetylation (Laaberki et al., 2011), whereas another system consisting of PatA1 and PatA2 multitransmembrane proteins and the PatB1 periplasmic $\mathrm{O}$-acetyltransferase is responsible of the $\mathrm{O}$-acetylation of secondary cell wall polysaccharides (Sychantha et al., 2017). Additionally, a second periplasmic protein with demonstrated acetylesterase activity -PatB2- has also been involved in $\mathrm{O}$-acetylation of additional cell wall components although the exact donor/acceptor substrate remains to be discovered (Sychantha et al., 2017). Hence, these organisms seem to have developed two different, independent systems for the translocation of acetyl-groups to then specifically $O$-acetylate the various wall polysaccharides utilizing members of two or more $\mathrm{O}$-acetyl transferase families.

\section{EVOLUTION OF PLANT POLYSACCHARIDE O-ACETYLATION MACHINERY}

Gram-positive bacteria, fungi, and mammals developed a one component machinery to $\mathrm{O}$-acetylate extracellular polymers. These systems use a single protein combining a multiple transmembrane domain translocating acetyl groups from the cytoplasm fused to a globular domain, containing a SGNH/GDSL-like catalytic motif. In plants, the protein domains and thus functionalities evolved into separate proteins (RWA, AXY9, and TBL protein families, respectively). As plants contain multiple wall polymers an expansion and increased diversification of the TBL protein family might have become necessary. Interestingly, although plant RWA proteins belong to the same sugar acyltransferase superfamily containing 10 transmembrane domains as bacterial OatAs, CnCas1p, and $\mathrm{HsCasD1}$, they lack the globular $\mathrm{O}$-acetyltransferase domain, indicating that plants need the additional involvement of other components such as members of the TBL family and/or AXY9 in order to $\mathrm{O}$-acetylate their wall polysaccharides. Accordingly, the globular domain of OatA or CnCas1p proteins contains the GDS and DxxH motifs similar to plant TBLs and AXY9 hinting their analogous functions. A similar separate, multiple component mechanism was also developed by Gram-negative bacteria in order to $\mathrm{O}$-acetylate extracellular polysaccharides, albeit likely arising through convergent evolution. The development of a multiple component system in these bacteria could reflect again a more complex wall with a variety of extracellular $O$-acetylated polysaccharides. In these bacteria, an increased diversification of the $\mathrm{O}$-acetyltransferases is also observed (e.g., PatB1/PatB2 in B. anthracis of AlgF, AlgJ and AlgX in P. aeruginosa).

All three families of proteins involved in $O$-acetylation of plant wall polysaccharides can be found in vascular plants but also in pteridophytes and bryophytes, including hornworts, mosses, and liverworts (Figure 2). A sequence comparison of nine representative embryophytic species showed that AXY9, TBL29, and RWA2 proteins seems to be highly conserved in dicots (Arabidopsis thaliana and Populus trichocarpa), monocots (Oryza sativa) and gymnosperms (Pinus radiata) sharing identities higher than 50\% and similarities around 75\% with the Arabidopsis representatives. Primitive plants such as Equisetum hyemale, liverworts (Marchantia polymorpha), hornworts (Phaeoceros carolinianus) and mosses (Physcomitrella patens) also contain highly conserved sequences sharing identity and similarity values around $40 \%$ and $60 \%$, respectively.

Land plants evolved from Charophyte green algae after their separation from Chlorophyte green algae (Lewis and McCourt, 2004; Becker and Marin, 2009). Although during the transition from an aquatic to terrestrial environment cell walls in both algae and plants have evolved independently (Niklas, 2004), it is still likely that some of the wall components have a common ancestry (Popper and Tuohy, 2010). Accordingly, the biosynthetic machinery of some of the polysaccharides present in a typical plant wall (e.g., xylan) can be traced back to the Charophyte green algae (Jensen et al., 2018). When probing algal genomes with the Arabidopsis RWA2 sequence, homologs can be found in dozens of green algae species including members of both the Chlorophyta (e.g., Volvox aureus or Nephroselmis pyriformis) and Charophyta (e.g., Klebsormidium subtile or Coleochaete scutata) divisions. However, algae seem not to encode proteins with sequence similarity to AXY9 or TBL29. Since algal RWA orthologs do not contain a GxxH and/or GSD domain required for polysaccharide $O$-acetylation algae might harbor additional, hitherto unidentified proteins that would be necessary for $O$-acetylation to occur. These results indicate that RWA proteins emerged earlier than AXY9 and the TBLs and suggest that green algae may also use a polysaccharide $O$-acetylation system based on RWA. The walls of several Chlorophyta and Charophyta species have been reported to contain plant-type wall polysaccharides such as xylan, mannans or XyG (Painter, 1983; Lahaye et al., 1994; Lahaye and Robic, 2007; Popper et al., 2011). Unfortunately, information about the $O$-acetylation status of these organisms is missing probably due to the alkali-based methods used during wall isolation.

\section{BIOLOGICAL SIGNIFICANCE OF POLYSACCHARIDE O-ACETYLATION}

$O$-acetylation of polysaccharides, including the various hemicelluloses and the pectic polysaccharides homogalacturonan and rhamnogalacturonan I, influences the polymer's physiochemical properties. Addition of $O$-acetyl-moieties contribute to the gelling properties and viscosity of the isolated polymers an important issue for food applications (Rombouts and Thibault, 1986; Huang et al., 2002). O-acetyl 
A

\subsection{AXY9}

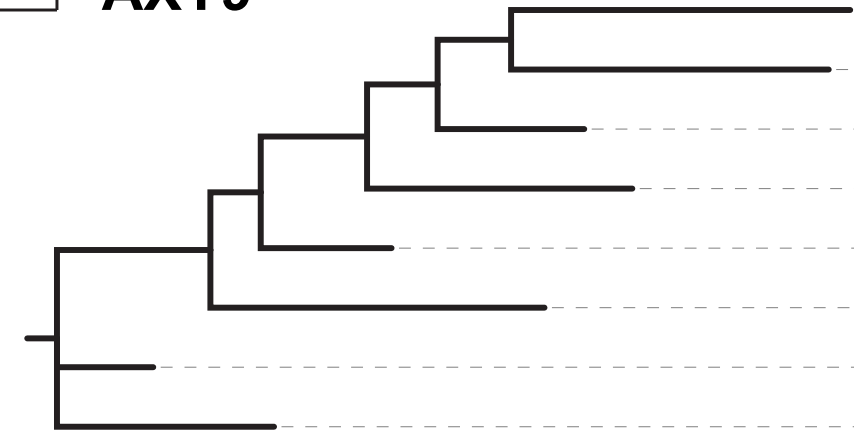

\begin{tabular}{|l|}
\hline Physcomitrella patens \\
\hline \hline Phaeoceros carolinianus \\
\hline \hline Marchantia polymorpha \\
\hline Equisetum hymale \\
Pinus radiata \\
\hline Oryza sativa \\
Populus trichocarpa \\
\hline Arabidopsis thaliana \\
\hline
\end{tabular}

B

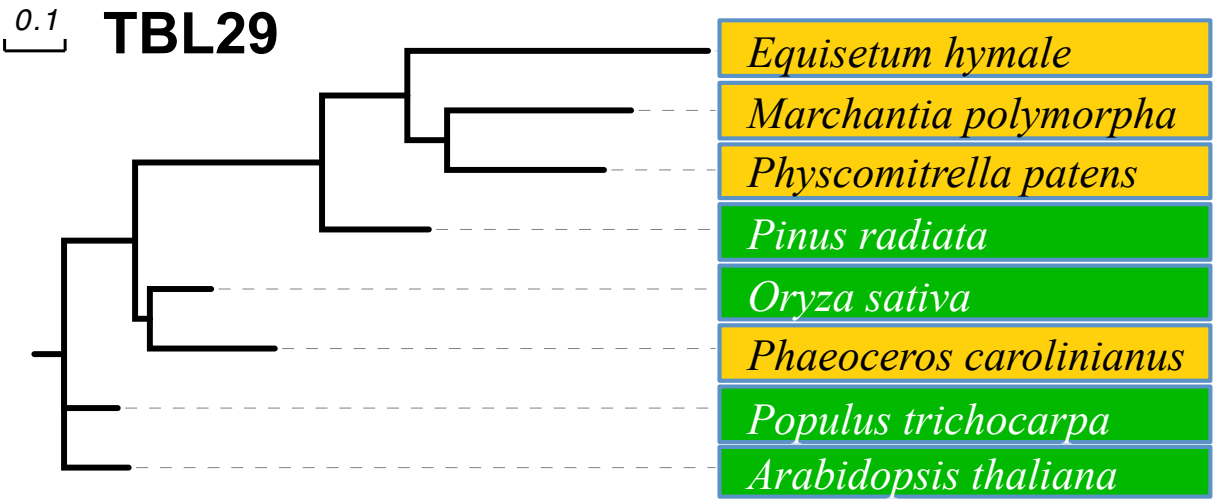

C

0.1 RWA2

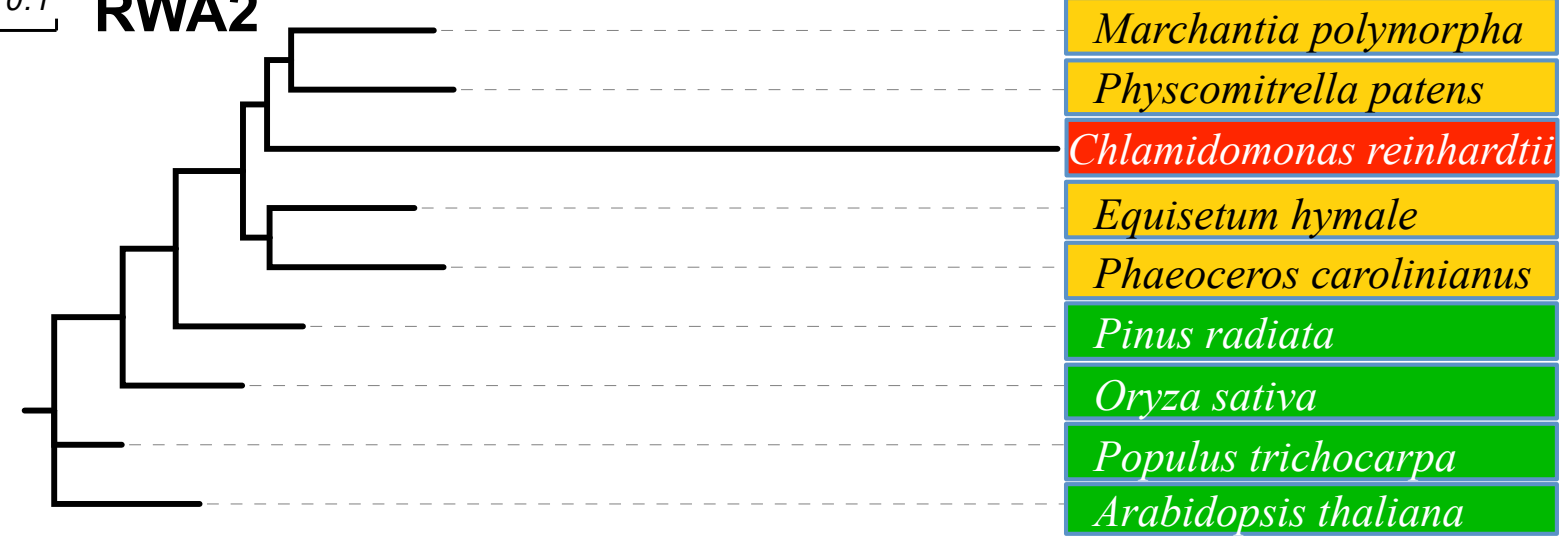

FIGURE 2 | Phylogenetic tree of AXY9, TBL, and RWA proteins. Likelihood tree of AXY9 (A), TBL29 (B), and RWA2 (C) protein homologs constructed from sequence alignment of selected species. Green: embryophytes (Arabidopsis thaliana and Populus trichocarpa, dicots; Oryza sativa, monocot; and Pinus radiata, gymnosperm). Orange: Bryophyta (Marchantia polymorpha, liverwort; Phaeoceros carolinianus, hornwort; and Physcomitrella patens, moss) and Pteridophyta (Equisetum hyemale, horsetail). Red: Algae (Chlamydomonas reinhardtii, green algae). Arabidopsis thaliana AXY9, TBL29, and RWA2 protein sequences (UniProtKB references Q9M9N9-1, Q9LY46-1, and Q0WW17-4, respectively) were used in Basic Alignment Search tool protein (BLASTp) against the 1,000 Plants Initiative databases (Matasci et al., 2014; https://db.cngb.org/blast/blastp/) with default parameters and the best hits for every specie were selected for phylogenetic analysis using the Phylogeny.fr web tool with default settings (Dereeper et al., 2008). This tool uses MUSCLE to align the sequences and the Gblocks program to eliminate poorly aligned positions and divergent regions. Phylogenetic trees were then constructed using PhyML using default parameters (Approximate Likelihood-Ratio Test) and the Evolview tool (http://www.evolgenius.info) was used to edit the graphical representation. 
substituents increase polysaccharide hydrophobicity and lead to conformational changes that influences interactions with other polymers, either supporting binding or due to steric hinderance abolish interaction (Busse-Wicher et al., 2014). As a result, de-O-acetylation through, e.g., alkali-treatments leads often to a decrease in solubility in aqueous environments and precipitation of polymers (Gibeaut et al., 2005; Busse-Wicher et al., 2016). Moreover, enzymatic attack of the polymer by glycosyl hydrolases is restricted due to steric hindrance in the vicinity of the target glycosidic bond (reviewed by Biely et al., 2016). As an application example in the wood industry, biomass chemical treatments include chaotropic alkali and acetic anhydride treatments in order to de-acetylate and re-acetylate the lignocellulosic polysaccharides, respectively, to modify the wood properties. De-acetylation improves properties for pulping, saccharification and fermentation due to the properties mentioned above. On the other hand, chemical acetylation of wood increases mechanical strength, durability and resistance to fungi, bacteria, and termites, as acetylation of xylan and mannan increases the stiffness and allows interactions with hydrophobic substances such as lignin (reviewed in Pawar et al., 2013). However, in non-lignified tissues, de-acetylation of primary wall polysaccharides (e.g., pectic polysaccharides) has been associated with increased cell wall stiffness probably due to a close spatial association between pectin and cellulose microfibrils (Gou et al., 2012; Orfila et al., 2012).

In planta the biological significance of a particular polysaccharide $\mathrm{O}$-acetylation pattern is diverse and in many cases not clear. For example, a complete lack of XyG sidechain $\mathrm{O}$-acetylation has no apparent impact on plant growth and development as the wild-type (WT)-like phenotypes of Arabidopsis axy4 and axy $4 L$ knockout mutants demonstrate. Reinforcing this notion, a natural Ty-O Arabidopsis accession displays an almost complete lack of XyG $O$-acetylation without detrimental plant morphological and developmental side-effects when grown in its native environment in the Highlands of Scotland (Gille et al., 2011b). However, O-acetylation seems to affect the aluminum binding capacity of XyG as demonstrated by an increased aluminum content in the hemicellulose fraction in axy 4 mutant roots compared to the WT when growing in the presence of this metal (Zhu et al., 2014). Yet, one cannot rule out the possibility that XyG $O$-acetylation may play a role in other environmental adaptation processes including specific stresses and/or growing conditions yet to be identified. In contrast to dicots such as Arabidopsis or poplar, in the grasses and plant members of the Solanaceae (such as tomato, tobacco, etc.) the glucan-backbone of XyG is partially $O$-acetylated (Gibeaut et al., 2005; Jia et al., 2005). This is caused by XyG O-acetyltransferases such as the Brachypodium $B d X y B A T 1$ that $O$-acetylate the non-xylosylated glucosyl backbone residues (Jia et al., 2005; Liu et al., 2016). When $B d X y B A T 1$ is expressed in Arabidopsis, the backbone of $\mathrm{XyG}$ becomes $\mathrm{O}$-acetylated reducing the degree of xylosylation of $\mathrm{XyG}$ indicating that $\mathrm{O}$-acetylation impacts negatively the addition of other substitutions (Liu et al., 2016). A reduction of the size of glycosyl side-chains of XyG lacking, e.g., the fucosyl and galactosyl residues leads to retarded plant growth (Pauly et al., 2013; Schultink et al., 2013).
It is thought that this dwarfism is caused by a distorted matrix polysaccharide secretion system caused by the poor solubility of the less substituted XyG (Jensen et al., 2012; Kong et al., 2015). However, the addition of backbone $O$-acetyl substituents to this lowly substituted XyG in the Arabidopsis mutant results in a reversion of the retarded growth (Liu et al., 2016). These results indicate that $\mathrm{O}$-acetylation of the XyG glucan-backbone is functionally equivalent to glycosyl-sidechains and might represent an energetically favorable strategy by replacing C5 and C6 carbon sugars with C2 acetates (Gibeaut et al., 2005; Jia et al., 2005; Gille and Pauly, 2012; Liu et al., 2016).

Mutants affected in xylan $O$-acetylation display multiple pleiotropic phenotypes including dwarfism, altered plant architecture and constitutive stress-related responses associated with a vascular collapse. Xylan is a major component of the walls present in the water conducting xylem. Hypoacetylation of xylan seems to affect the physical strength of the xylem walls, as they are not able to resist the negative water pressure generated during water transport. As a consequence, mutants affected in members of the AXY9, RWA or particular TBLs that impact xylan $\mathrm{O}$-acetylation all display alterations in plant growth and development. In Arabidopsis, the axy9-2 mutant shows an 80\% reduction in xylan $O$-acetylation and a strong growth arrest (Schultink et al., 2015), whereas the quadruple rwa mutant shows a $42 \%$ reduction in xylan $O$-acetylation with a reduction in secondary wall thickening and collapsed xylem morphology (Lee et al., 2011). Regarding the TBL family, only tbl29/esk1 single mutant alleles, with a $40 \%$ reduction in xylan $O$-acetylation, show a clear irregular xylem phenotype. Several other tbl single mutants with only minor reductions in xylan $O$-acetylation show only additive effects in the corresponding double, triple or multiple mutant combinations in vascular development and plant growth in several plant species (Yuan et al., 2016a,b,c; Gao et al., 2017).

In addition to the xylem collapse and growth arrest, xylan hypoacetylation has also been associated with other developmental and stress-related phenotypes. tbl29/esk1 mutant alleles also show stress-related pleiotropic phenotypes such as increased tolerance to drought, salt or freezing, likely an indirect consequence of the collapsed xylem (Xin and Browse, 1998; Xin et al., 2007; Bouchabke-Coussa et al., 2008; Lefebvre et al., 2011; Ramirez et al., 2018). Intriguingly, several lines of evidence seem to indicate that low xylan acetylation may not be directly responsible for these observed phenotypes. For example, expression of fungal acetyl-esterases in Arabidopsis and Brachypodium causes post-synthetic de-acetylation of xylan but it does not impact plant development or xylem morphology (Pogorelko et al., 2013b). Most recently, the identification of two tbl29 suppressors, where the xylem collapse and growth arrest are recovered but the wall/xylan acetate remains reduced, strongly supports these observations. KAKTUS (KAK) loss of function increases stem diameter and activates the development of larger tracheary elements. As a consequence, kak mutations are able to recover almost completely from tbl29/esk1-associated dwarfism without affecting wall acetate content. Although KAK has been described previously as an endoreduplication repressor affecting trichome morphology, the mechanism how it regulates 
vascular development is not known (Downes et al., 2003; El Refy et al., 2003; Bensussan et al., 2015). Altered biosynthesis and/or perception of some plant hormones (e.g., abscisic acid; ABA) have been suggested to play a role in the pleiotropic phenotype of tbl29/esk1. tbl29/esk1 alleles show increased ABA levels and enhanced expression of several ABA-dependent genes, but genetic evidence discarded that this hormonal pathway is directly responsible for the phenotypes of tbl29/esk1 plants. Double mutants blocking ABA biosynthesis or perception in a tbl29/esk1 background are not able to recover the developmental defects shown by the tbl29/esk1 single mutant. Moreover, increased ABA perception and tbl29/esk1 down-regulation seems to have additive effects on drought tolerance, suggesting that they affect independent pathways (Lefebvre et al., 2011). These findings indicate that altered $\mathrm{ABA}$ levels are more a consequence of the pleiotropic phenotype of the tbl29/esk1 mutant rather than the cause. In contrast, it has been shown that blocking strigolactone (SL) synthesis in tbl29/esk1 plants (i.e., tbl29 max4 double mutants) is able to completely suppress both developmental defects and increased freezing tolerance without affecting the reduced acetate content (Ramirez et al., 2018). In addition, exogenous applications of a synthetic SL to tbl29 max4 plants result in dwarfism and collapsed xylem, further confirming that these phenotypes are SL-dependent. This suggests that an altered SL pathway could be directly involved in leading to the pleiotropic phenotypes associated to the tbl29/esk1 mutants. As SLs are hormones involved in the regulation of multiple plant processes including stem elongation, secondary growth, leaf expansion and adaptation to abiotic stress (reviewed in Waters et al., 2017), this opens the possibility that xylan hypoacetylation could be perceived by an unknown mechanism triggering the activation a SL-dependent response regulating xylem development (Ramirez et al., 2018).

In addition to acetate, xylan can also be substituted with (methyl-)glucuronic acid (methyl-GlcA) residues by xylan glucuronosyltransferases termed GUX. Together, these decorations have been found to be important for xylan-cellulose binding (Mortimer et al., 2010; Rennie et al., 2012; Bromley et al., 2013; Busse-Wicher et al., 2014). Actually, vascular plants seem to generate a specific xylan decoration pattern as acetate and GlcA are found spaced on even-numbered residues in the xylan backbone (Busse-Wicher et al., 2016). Recently, it has been shown that in Arabidopsis, TBL29/ESK1-dependent xylan $O$-acetylation is required for the generation of the evenpatterned GlcA substitutions (Grantham et al., 2017). In a tbl29/esk1 mutant, where xylan acetylation is reduced, GUX1 is unable to maintain the GlcA decoration pattern suggesting that a correct $O$-acetylation pattern is required for the addition of GlcA residues. As a consequence of this uneven substitution, xylan might not be able to acquire the typical twofold screw ribbon conformation impeding its docking onto the hydrophilic face of a cellulose microfibril to form semicrystalline xylanocellulose fibrils (Grantham et al., 2017). Intriguingly, expression of GUX1 in vascular tissue under the control of a tissue specific promoter is able to rescue the tbl29/esk1 mutant growth defects indicating that xylan functionality is restored (Xiong et al., 2015). GUX1 is able to glucuronosylate additional available positions on the xylan backbone due to the absence of $O$-acetyl-groups in $t b l 29$. Glucuronosylation of xylan can thus be considered functionally equivalent to $\mathrm{O}$-acetylation in vivo. This agrees with the notion that the addition of $\mathrm{O}$-acetyl substituents ( $\mathrm{C} 2$ units) to wall polysaccharides instead of sugars (C5-C6) could have evolved as a more energetically favorable strategy as described above for XyG. Other TBL proteins than TBL29/ESK1 participate in the regiospecific $O$-acetylation of xylan (Zhong et al., 2017), suggesting the existence of a precisely regulated mechanism to create a tissue-specific $O$-acetylation pattern in xylan in order to adequately interact with cellulose and likely other cell wall components.

$O$-acetylation of pectic polysaccharides has also been associated with plant signaling processes. rwa2 mutant alleles show increased resistance to the necrotrophic fungal pathogen Botrytis cinerea accompanied by leaf surface defects including trichome collapse, enhanced leave permeability and altered cuticle formation (Manabe et al., 2011; Nafisi et al., 2015). As these defects have not been observed in other mutants affected in hemicellulosic polysaccharide $O$-acetylation, it has been speculated that these phenotypes may be caused by pectin hypoacetylation although direct evidence is still lacking (Nafisi et al., 2015). Other reports have associated reduced pectin $\mathrm{O}$-acetylation with increased disease resistance. For example, plants overexpressing a fungal rhamnogalacturonan acetylesterase constitutively activate defense responses and show increased resistance to pathogens (Pogorelko et al., 2013b). Since a similar response has been observed after application of oligogalacturonide fragments (OGs) and more efficiently by partially acetylated OGs, it has been proposed that pectin $O$-acetylation might be involved in a cell wall integrity maintenance system (Randoux et al., 2010; Pogorelko et al., 2013a).

Recently, pectin $O$-acetylation has been also proposed to regulate other important developmental processes such as photomorphogenesis (Sinclair et al., 2017). Both the tbr mutant, affected in a putative pectin acetyltransferase, and the rwa2 mutant, show a photomorphogenic response when grown in the dark. This phenotype can be restored by adding small homogalacturonan fragments and thus pectin $O$-acetylation might regulate a dark signal involved in a complex network of light-dependent seedling development (Sinclair et al., 2017).

\section{OPEN QUESTIONS}

There are still open questions regarding the mechanism of polysaccharide $O$-acetylation not only in plants but also in bacteria, fungi, and mammals. First, the identity of the acetyldonor and the detailed mechanism of translocation through the Golgi membrane are not known in any of these organisms. Although it is likely that the cytosolic acetyl-CoA pool is tapped for this purpose, acetyl-CoA itself is likely not transferred. Studying this process is challenging as the likely responsible protein contains multiple transmembrane domains. Second, the exact mechanism of the transfer of an acetyl group from a donor to the hydroxyl group of an acceptor sugar remains unknown, 
although mechanistic insights became recently available from bacterial OatA proteins (Sychantha and Clarke, 2018). Recent reports in bacteria have suggested a direct acylation of the OatA protein following a ping-pong bi-bi mechanism of action where the acetyl group is covalently attached to the catalytic Ser residue of the enzyme before being transferred to the substrate. A similar acetyl-enzyme intermediate has also been proposed in the Gram-negative PatA/PatB mode of action, where PatB $O$-acetyltransferases could form a complex with the acetyl-bound PatA membrane proteins precluding free water from accessing the active site, preventing the hydrolysis of the translocated acetyl group ensuring an efficient acetate transfer (Moynihan and Clarke, 2010). The existence of likely intermediary steps as suggested in other Gram-negative bacteria systems (e.g., $\mathrm{AlgI} / \mathrm{AlgF} / \mathrm{Alg} / \mathrm{AlgX}$ ) could implicate the formation of a multiprotein complex for the $O$-acetylation of extracellular polysaccharides. A RWA/AXY9/TBL complex formation could also be conserved in plant systems, although mechanistic details are still missing. Comparison of the various polysaccharide $O$-acetylation systems raises the question of the evolution of the various $O$-acetylation mechanism - in essence why multiple proteins are required for this process in some species while in other species apparently a single protein suffices. Third, the transferases responsible for the $O$-acetylation of some wall polymers (e.g., mannans, pectins, or lignin) remain

\section{REFERENCES}

Anantharaman, V., and Aravind, L. (2010). Novel eukaryotic enzymes modifying cell-surface biopolymers. Biol. Direct 5:1. doi: 10.1186/1745-6150-5-1

Arming, S., Wipfler, D., Mayr, J., Merling, A., Vilas, U., Schauer, R., et al. (2011). The human Cas1 protein: a sialic acid-specific O-acetyltransferase? Glycobiology 21, 553-564. doi: 10.1093/glycob/cwq153

Baker, P., Ricer, T., Moynihan, P. J., Kitova, E. N., Walvoort, M. T., Little, D. J., et al. (2014). P. aeruginosa SGNH hydrolase-like proteins AlgJ and AlgX have similar topology but separate and distinct roles in alginate acetylation. PLoS Pathog. 10:e1004334. doi: 10.1371/journal.ppat.1004334

Banfield, D. K. (2011). Mechanisms of protein retention in the Golgi. Cold Spring Harb. Perspect. Biol. 3:a005264. doi: 10.1101/cshperspect.a005264

Baumann, A. M., Bakkers, M. J., Buettner, F. F., Hartmann, M., Grove, M., Langereis, M. A., et al. (2015). 9-O-Acetylation of sialic acids is catalysed by CASD1 via a covalent acetyl-enzyme intermediate. Nat. Commun. 6:7673. doi: $10.1038 /$ ncomms 8673

Becker, B., and Marin, B. (2009). Streptophyte algae and the origin of embryophytes. Ann. Bot. 103, 999-1004. doi: 10.1093/aob/mcp044

Bensussan, M., Lefebvre, V., Ducamp, A., Trouverie, J., Gineau, E., Fortabat, M. N., et al. (2015). Suppression of dwarf and irregular xylem phenotypes generates low-acetylated biomass lines in Arabidopsis. Plant Physiol. 168, 452-463. doi: 10.1104/pp.15.00122

Biely, P., Singh, S., and Puchart, V. (2016). Towards enzymatic breakdown of complex plant xylan structures: state of the art. Biotechnol. Adv. 34, 1260-1274. doi: 10.1016/j.biotechadv.2016.09.001

Bischoff, V., Nita, S., Neumetzler, L., Schindelasch, D., Urbain, A., Eshed, R., et al. (2010a). TRICHOME BIREFRINGENCE and its homolog AT5G01360 encode plant-specific DUF231 proteins required for cellulose biosynthesis in Arabidopsis. Plant Physiol. 153, 590-602. doi: 10.1104/pp.110.153320

Bischoff, V., Selbig, J., and Scheible, W. R. (2010b). Involvement of TBL/DUF231 proteins into cell wall biology. Plant Signal. Behav. 5, 1057-1059.

Bouchabke-Coussa, O., Quashie, M. L., Seoane-Redondo, J., Fortabat, M. N., Gery, C., Yu, A., et al. (2008). ESKIMO1 is a key gene involved in water economy as well as cold acclimation and salt tolerance. BMC Plant Biol. 8:125. doi: 10.1186/1471-2229-8-125 to be discovered, albeit it is likely that members of the TBL family are involved. The identification and characterization of such proteins is not only needed to understand the wall $O$-acetylation mechanism of particular wall polysaccharides, but also to gain insights into the function of the $O$-acetyl substituent on this polymer. Fourth, the recent advent of identifying the genes responsible for polysaccharide $\mathrm{O}$-acetylation and their genetic manipulation in vivo lead to the discovery of intriguing function of this substituent. However, at this stage the phenotypic results are rather descriptive and additional research in the future is required to ascertain causal relationships as well as mechanistic insights into polymer interactions, cellular sensing and responses.

\section{AUTHOR CONTRIBUTIONS}

MP and VR designed and wrote the manuscript.

\section{FUNDING}

This research was supported by CEPLAS (Cluster of Excellence on Plant Sciences - Deutsche Forschungsgemeinschaft EXC1028) and Marie Curie PIOF-GA-2013-623553 to VR.

Bromley, J. R., Busse-Wicher, M., Tryfona, T., Mortimer, J. C., Zhang, Z., Brown, D. M., et al. (2013). GUX1 and GUX2 glucuronyltransferases decorate distinct domains of glucuronoxylan with different substitution patterns. Plant J. 74, 423-434. doi: 10.1111/tpj.12135

Busse-Wicher, M., Gomes, T. C., Tryfona, T., Nikolovski, N., Stott, K., Grantham, N. J., et al. (2014). The pattern of xylan acetylation suggests xylan may interact with cellulose microfibrils as a twofold helical screw in the secondary plant cell wall of Arabidopsis thaliana. Plant J. 79, 492-506. doi: 10.1111/tpj.12575

Busse-Wicher, M., Li, A., Silveira, R. L., Pereira, C. S., Tryfona, T., Gomes, T. C. F., et al. (2016). Evolution of xylan substitution patterns in gymnosperms and angiosperms: implications for xylan interaction with cellulose. Plant Physiol. 171, 2418-2431. doi: 10.1104/pp.16.00539

Chundawat, S. P. S., Vismeh, R., Sharma, L. N., Humpula, J. F., da Costa Sousa, L., Chambliss, C. K., et al. (2010). Multifaceted characterization of cell wall decomposition products formed during ammonia fiber expansion (AFEX ${ }^{\mathrm{TM}}$ ) and dilute acid based pretreatments. Bioresour. Technol. 101, 8429-8438. doi: 10.1016/j.biortech.2010.06.027

Clarke, A. J., Strating, H., and Blackburn, N. T. (2000). "Pathways for the O-acetylation of bacterial cell wall polymers," in Glycomicrobiology, ed. R. J. Doyle (New York, NY: Plenum Publishing Co. Ltd), 187-212.

de Souza, A., Hull, P. A., Gille, S., and Pauly, M. (2014). Identification and functional characterization of the distinct plant pectin esterases PAE8 and PAE9 and their deletion mutants. Planta 240, 1123-1138. doi: 10.1007/s00425-0142139-6

Del Río, J. C., Marques, G., Rencoret, J., Martínez, A. T., and Gutiérrez, A. (2007). Occurrence of naturally acetylated lignin units. J. Agric. Food Chem. 55, 5461-5468. doi: 10.1021/jf0705264

Dereeper, A., Guignon, V., Blanc, G., Audic, S., Buffet, S., Chevenet, F., et al. (2008). Phylogeny.fr: robust phylogenetic analysis for the non-specialist. Nucleic Acids Res. 36, W465-W469. doi: 10.1093/nar/gkn180

Downes, B. P., Stupar, R. M., Gingerich, D. J., and Vierstra, R. D. (2003). The HECT ubiquitin-protein ligase (UPL) family in Arabidopsis: UPL3 has a specific role in trichome development. Plant J. 35, 729-742. doi: 10.1046/j.1365-313X.2003. 01844.x

El Refy, A., Perazza, D., Zekraoui, L., Valay, J. G., Bechtold, N., Brown, S., et al. (2003). The Arabidopsis KAKTUS gene encodes a HECT protein and controls 
the number of endoreduplication cycles. Mol. Genet. Genomics 270, 403-414. doi: 10.1007/s00438-003-0932-1

Fatland, B. L., Nikolau, B. J., and Wurtele, E. S. (2005). Reverse genetic characterization of cytosolic acetyl-CoA generation by ATP-citrate lyase in Arabidopsis. Plant Cell 17, 182-203. doi: 10.1105/tpc.104.026211

Gao, Y., He, C., Zhang, D., Liu, X., Xu, Z., Tian, Y., et al. (2017). Two trichome birefringence-like proteins mediate xylan acetylation, which is essential for leaf blight resistance in rice. Plant Physiol. 173, 470-481. doi: 10.1104/pp.16.01618

Gibeaut, D. M., Pauly, M., Bacic, A., and Fincher, G. B. (2005). Changes in cell wall polysaccharides in developing barley (Hordeum vulgare) coleoptiles. Planta 221, 729-738. doi: 10.1007/s00425-005-1481-0

Gille, S., Cheng, K., Skinner, M. E., Liepman, A. H., Wilkerson, C. G., and Pauly, M. (2011a). Deep sequencing of voodoo lily (Amorphophallus konjac): an approach to identify relevant genes involved in the synthesis of the hemicellulose glucomannan. Planta 234, 515-526. doi: 10.1007/s00425-011-1422-z

Gille, S., de Souza, A., Xiong, G., Benz, M., Cheng, K., Schultink, A., et al. (2011b). O-acetylation of Arabidopsis hemicellulose xyloglucan requires AXY4 or AXY4L, proteins with a TBL and DUF231 domain. Plant Cell 23, 4041-4053. doi: $10.1105 /$ tpc. 111.091728

Gille, S., and Pauly, M. (2012). O-acetylation of plant cell wall polysaccharides. Front. Plant Sci. 3:12. doi: 10.3389/fpls.2012.00012

Gou, J. Y., Miller, L. M., Hou, G., Yu, X. H., Chen, X. Y., and Liu, C. J. (2012). Acetylesterase-mediated deacetylation of pectin impairs cell elongation, pollen germination, and plant reproduction. Plant Cell 24, 50-65. doi: 10.1105/tpc.111. 092411

Grantham, N. J., Wurman-Rodrich, J., Terrett, O. M., Lyczakowski, J. J., Stott, K., Iuga, D., et al. (2017). An even pattern of xylan substitution is critical for interaction with cellulose in plant cell walls. Nat. Plants 3, 859-865. doi: 10.1038/s41477-017-0030-8

Ha, R., Frirdich, E., Sychantha, D., Biboy, J., Taveirne, M. E., Johnson, J. G., et al. (2016). Accumulation of peptidoglycan O-acetylation leads to altered cell wall biochemistry and negatively impacts pathogenesis factors of Campylobacter jejuni. J. Biol. Chem. 291, 22686-22702. doi: 10.1074/jbc.M116.746404

Helle, S., Cameron, D., Lam, J., and White, B. (2003). Effect of inhibitory compounds found in biomass hydrolysates on growth and xylose fermentation by a genetically engineered strain of S. cerevisiae. Enzyme Microb. Technol. 33, 786-792. doi: 10.1016/S0141-0229(03)00214-X

Hoffman, M., Jia, Z., Pena, M., Cash, M., Harper, A., Blackburn, A., et al. (2005). Structural analysis of xyloglucans in the primary cell walls of plants in the subclass Asteridae. Carbohydr. Res. 340, 1826-1840. doi: 10.1016/j.carres.2005. 04.016

Hsieh, Y. S. Y., and Harris, P. J. (2009). Xyloglucans of monocotyledons have diverse structures. Mol. Plant 2, 943-965. doi: 10.1093/mp/ssp061

Huang, L., Takahashi, R., Kobayashi, S., Kawase, T., and Nishinari, K. (2002). Gelation behavior of native and acetylated konjac glucomannan. Biomacromolecules 3, 1296-1303. doi: 10.1021/bm0255995

Ishii, T. (1991). Acetylation at O-2 of arabinofuranose residues in feruloylated arabinoxylan from bamboo shoot cell-walls. Phytochemistry 30, 2317-2320. doi: 10.1016/0031-9422(91)83639-3

Ishii, T. (1997). O-acetylated oligosaccharides from pectins of potato tuber cell walls. Plant Physiol. 113, 1265-1272. doi: 10.1104/pp.113.4.1265

Janbon, G., Himmelreich, U., Moyrand, F., Improvisi, L., and Dromer, F. (2001). Caslp is a membrane protein necessary for the O-acetylation of the Cryptococcus neoformans capsular polysaccharide. Mol. Microbiol. 42, 453-467. doi: 10.1046/j.1365-2958.2001.02651.x

Jensen, J. K., Busse-Wicher, M., Poulsen, C. P., Fangel, J. U., Smith, P. J., Yang, J. Y., et al. (2018). Identification of an algal xylan synthase indicates that there is functional orthology between algal and plant cell wall biosynthesis. New Phytol. 218, 1049-1060. doi: 10.1111/nph.15050

Jensen, J. K., Schultink, A., Keegstra, K., Wilkerson, C. G., and Pauly, M. (2012). RNA-Seq analysis of developing nasturtium seeds (Tropaeolum majus): identification and characterization of an additional galactosyltransferase involved in xyloglucan biosynthesis. Mol. Plant 5, 984-992. doi: 10.1093/mp/ sss032

Jia, Z., Cash, M., Darvill, A., and York, W. (2005). NMR characterization of endogenously O-acetylated oligosaccharides isolated from tomato (Lycopersicon esculentum) xyloglucan. Carbohydr. Res. 340, 1818-1825. doi: $10.1016 /$ j.carres.2005.04.015
Johnson, A. M., Kim, H., Ralph, J., and Mansfield, S. D. (2017). Natural acetylation impacts carbohydrate recovery during deconstruction of Populus trichocarpa wood. Biotechnol. Biofuels 10:48. doi: 10.1186/s13068-017-0734-z

Kabel, M. A., de Waard, P., Schols, H. A., and Voragen, A. G. J. (2003). Location of O-acetyl substituents in xylo-oligosaccharides obtained from hydrothermally treated eucalyptus wood. Carbohydr. Res. 338, 69-77. doi: 10.1016/S00086215(02)00351-8

Kiefer, L., York, W., Darvill, A., and Albersheim, P. (1989). Structure of plantcell walls.27. Xyloglucan isolated from suspension-cultured sycamore cell-walls is o-acetylated. Phytochemistry 28, 2105-2107. doi: 10.1016/S0031-9422(00) 97928-7

Kim, S. Y., Kim, J. G., Lee, B. M., and Cho, J. Y. (2009). Mutational analysis of the gum gene cluster required for xanthan biosynthesis in Xanthomonas oryzae $\mathrm{pv}$ oryzae. Biotechnol. Lett. 31, 265-270. doi: 10.1007/s10529-008-9858-3

Kong, Y., Peña, M. J., Renna, L., Avci, U., Pattathil, S., Tuomivaara, S. T., et al. (2015). Galactose-depleted xyloglucan is dysfunctional and leads to dwarfism in Arabidopsis. Plant Physiol. 167, 1296-1306. doi: 10.1104/pp.114.255943

Laaberki, M. H., Pfeffer, J., Clarke, A. J., and Dworkin, J. (2011). O-acetylation of peptidoglycan is required for proper cell separation and s-layer anchoring in Bacillus anthracis. J. Biol. Chem. 286, 5278-5288. doi: 10.1074/jbc.M110.183236

Lahaye, M., Jegou, D., and Buléon, A. (1994). Chemical characteristics of insoluble glucans from the cell wall of the marine green alga Ulva lactuca (L.) Thuret. Carbohydr. Res. 262, 115-125. doi: 10.1016/0008-6215(94)84008-3

Lahaye, M., and Robic, A. (2007). Structure and functional properties of ulvan, a polysaccharide from green seaweeds. Biomacromolecules 8, 1765-1774. doi: $10.1021 / \mathrm{bm} 061185 \mathrm{q}$

Lee, C., Teng, Q., Zhong, R., and Ye, Z.-H. (2011). The four Arabidopsis reduced wall acetylation genes are expressed in secondary wall-containing cells and required for the acetylation of xylan. Plant Cell Physiol. 52, 1289-1301. doi: $10.1093 /$ pcp/pcr075

Lefebvre, V., Fortabat, M. N., Ducamp, A., North, H. M., Maia-Grondard, A., Trouverie, J., et al. (2011). ESKIMO1 disruption in Arabidopsis alters vascular tissue and impairs water transport. PLoS One 6:e16645. doi: 10.1371/journal. pone. 0016645

Lewis, L. A., and McCourt, R. M. (2004). Green algae and the origin of land plants. Am. J. Bot. 91, 1535-1556. doi: 10.3732/ajb.91.10.1535

Liu, L., Hsia, M. M., Dama, M., Vogel, J., and Pauly, M. (2016). A xyloglucan backbone 6-O-acetyltransferase from Brachypodium distachyon modulates xyloglucan xylosylation. Mol. Plant 9, 615-617. doi: 10.1016/j.molp.2015.11.004

Lourenço, A., Rencoret, J., Chemetova, C., Gominho, J., Gutierrez, A., del Rio, J. C., et al. (2016). Lignin composition and structure differs between xylem, phloem and phellem in Quercus suber. Front. Plant Sci. 7:1612. doi: 10.3389/fpls.2016. 01612

Lundqvist, J., Teleman, A., Junel, L., Zacchi, G., Dahlman, O., Tjerneld, F., et al. (2002). Isolation and characterization of galactoglucomannan from spruce (Picea abies). Carbohydr. Polym. 48, 29-39. doi: 10.1021/jf303741h

Manabe, Y., Nafisi, M., Verhertbruggen, Y., Orfila, C., Gille, S., Rautengarten, C., et al. (2011). Loss-of-function mutation of REDUCED WALL ACETYLATION2 in Arabidopsis leads to reduced cell wall acetylation and increased resistance to Botrytis cinerea. Plant Physiol. 155, 1068-1078. doi: 10.1104/pp.110.168989

Manabe, Y., Verhertbruggen, Y., Gille, S., Harholt, J., Chong, S. L., Pawar, P. M., et al. (2013). Reduced wall acetylation proteins play vital and distinct roles in cell wall O-acetylation in Arabidopsis. Plant Physiol. 163, 1107-1117. doi: 10.1104/pp.113.225193

Matasci, N., Hung, L. H., Yan, Z., Carpenter, E. J., Wickett, N. J., Mirarab, S., et al. (2014). Data access for the 1,000 Plants (1KP) project. Gigascience 3, 10-17. doi: $10.1186 / 2047-217 X-3-17$

Mortimer, J. C., Miles, G. P., Brown, D. M., Zhang, Z., Segura, M. P., Weimar, T., et al. (2010). Absence of branches from xylan in Arabidopsis gux mutants reveals potential for simplification of lignocellulosic biomass. Proc. Natl. Acad. Sci. U.S.A. 107, 17409-17414. doi: 10.1073/pnas.1005456107

Moynihan, P. J., and Clarke, A. J. (2010). O-acetylation of peptidoglycan in Gram-negative bacteria: identification and characterization of peptidoglycan O-acetyltransferase in Neisseria gonorrhoeae. J. Biol. Chem. 285, 13264-13273. doi: 10.1074/jbc.M110.107086

Moynihan, P. J., and Clarke, A. J. (2011). O-Acetylated peptidoglycan: controlling the activity of bacterial autolysins and lytic enzymes of innate immune systems. Int. J. Biochem. Cell Biol. 43, 1655-1659. doi: 10.1016/j.biocel.2011.08.007 
Moynihan, P. J., Sychantha, D., and Clarke, A. J. (2014). Chemical biology of peptidoglycan acetylation and deacetylation. Bioorg. Chem. 54, 44-50. doi: 10.1016/j.bioorg.2014.03.010

Nafisi, M., Stranne, M., Fimognari, L., Atwell, S., Martens, H. J., and Pedas, P. R. (2015). Acetylation of cell wall is required for structural integrity of the leaf surface and exerts a global impact on plant stress responses. Front. Plant Sci. 6:550. doi: $10.3389 /$ fpls.2015.00550

Niklas, K. J. (2004). The cell walls that bind the tree of life. Bioscience 54, 831-841. doi: 10.1641/0006-3568(2004)054[0831:TCWTBT]2.0.CO;2

Obel, N., Erben, V., Schwarz, T., Kuhnel, S., Fodor, A., and Pauly, M. (2009). Microanalysis of plant cell wall polysaccharides. Mol. Plant 2, 922-932. doi: $10.1093 / \mathrm{mp} / \mathrm{ssp} 046$

Oliver, D. J., Nikolau, B. J., and Wurtele, E. S. (2009). Acetyl CoA - life at the metabolic nexus. Plant Sci. 176, 597-601. doi: 10.1016/j.plantsci.2009.02.005

O’Neill, M. A., Ishii, T., Albersheim, P., and Darvill, A. G. (2004). Rhamnogalacturonan II: structure and function of a borate cross-linked cell wall pectic polysaccharide. Annu. Rev. Plant Biol. 55, 109-139. doi: 10.1146/annurev.arplant.55.031903.141750

Orfila, C., Dal Degan, F., Jorgensen, B., Scheller, H. V., Ray, P. M., and Ulvskov, P. (2012). Expression of mung bean pectin acetyl esterase in potato tubers: effect on acetylation of cell wall polymers and tuber mechanical properties. Planta 236, 185-196. doi: 10.1007/s00425-012-1596-z

Pacios Bras, C., Jordaì, M. A., Wijfjes, A. H. M., Harteveld, M., Stuurman, N., Thomas-Oates, J. E., et al. (2000). A Lotus japonicus nodulation system based on heterologous expression of the fucosyl transferase NodZ and the acetyl transferase NolL in Rhizobium leguminosarum. Mol. Plant Microbe Interact. 13, 475-479. doi: 10.1094/MPMI.2000.13.4.475

Painter, T. J. (1983). "Algal polysaccharides," in The Polysaccharides, Vol. 2, ed. G. O. Aspinall (New York, NY: Academic Press), 195-285.

Pauly, M. (1999). Development of Analytical Tools to Study Plant Cell Wall Xyloglucan. Ph.D. thesis, Aachen, Shaker Verlag.

Pauly, M., Gille, S., Liu, L. F., Mansoori, N., de Souza, A., Schultink, A., et al. (2013). Hemicellulose biosynthesis. Planta 238, 627-642. doi: 10.1007/s00425013-1921-1

Pauly, M., and Keegstra, K. (2010). Plant cell wall polymers as precursors for biofuels. Curr. Opin. Plant Biol. 13, 304-311. doi: 10.1016/j.pbi.2009.12.009

Pauly, M., and Scheller, H. (2000). O-acetylation of plant cell wall polysaccharides: identification and partial characterization of a rhamnogalacturonan O-acetyltransferase from potato suspension-cultured cells. Planta 210, 659-667. doi: $10.1007 /$ s004250050057

Pawar, P. M., Koutaniemi, S., Tenkanen, M., and Mellerowicz, E. J. (2013). Acetylation of woody lignocellulose: significance and regulation. Front. Plant Sci. 4:118. doi: 10.3389/fpls.2013.00118

Pawar, P. M., Ratke, C., Balasubramanian, V. K., Chong, S. L., Gandla, M. L., Adriasola, M., et al. (2017). Downregulation of RWA genes in hybrid aspen affects xylan acetylation and wood saccharification. New Phytol. 214, 1491-1505. doi: 10.1111/nph.14489

Pogorelko, G., Lionetti, V., Bellincampi, D., and Zabotina, O. (2013a). Cell wall integrity: targeted post-synthetic modifications to reveal its role in plant growth and defense against pathogens. Plant Signal. Behav. 8:e25435. doi: 10.4161/psb. 25435

Pogorelko, G., Lionetti, V., Fursova, O., Sundaram, R. M., Qi, M., Whitham, S. A., et al. (2013b). Arabidopsis and Brachypodium distachyon transgenic plants expressing Aspergillus nidulans acetylesterases have decreased degree of polysaccharide acetylation and increased resistance to pathogens. Plant Physiol. 162, 9-23. doi: 10.1104/pp.113.214460

Popper, Z. A., Gurvan, M., Hervé, C., Domozych, D. S., Willats, W. G. T., Tuohy, M. G., et al. (2011). Evolution and diversity of plant cell walls: from algae to flowering plants. Annu. Rev. 62, 567-590. doi: 10.1146/annurev-arplant042110-103809

Popper, Z. A., and Tuohy, M. G. (2010). Beyond the green: understanding the evolutionary puzzle of plant and algal cell walls. Plant Physiol. 153, 373-383. doi: 10.1104/pp.110.158055

Ralph, J. (1996). An unusual lignin from kenaf. J. Nat. Prod. 59, 341-342. doi: $10.1021 / \mathrm{np} 960143 \mathrm{~s}$

Ramirez, V., Xiong, G., Mashiguchi, K., Yamaguchi, S., and Pauly, M. (2018). Growth- and stress-related defects associated with wall hypoacetylation are strigolactone-dependent. Plant Direct 2:e00062. doi: 10.1002/pld3.62
Randoux, B., Renard-Merlier, D., Mulard, G., Rossard, S., Duyme, F., Sanssené, J., et al. (2010). Distinct defenses induced in wheat against powdery mildew by acetylated and nonacetylated oligogalacturonides. Phytopathology 100, 13521363. doi: 10.1094/PHYTO-03-10-0086

Rennie, E. A., Hansen, S. F., Baidoo, E. E., Hadi, M. Z., Keasling, J. D., and Scheller, H. V. (2012). Three members of the Arabidopsis glycosyltransferase family 8 are xylan glucuronosyltransferases. Plant Physiol. 159, 1408-1417. doi: $10.1104 /$ pp.112.200964

Rombouts, M., and Thibault, J. F. (1986). Enzymatic and chemical degradation and the fine-structure of pectins from sugar-beet pulp. Carbohydr. Res. 154, 189-203. doi: 10.1016/S0008-6215(00)90032-6

Schultink, A., Cheng, K., Park, Y. B., Cosgrove, D. J., and Pauly, M. (2013). The identification of two arabinosyltransferases from tomato reveals functional equivalency of xyloglucan side chain substituents. Plant Physiol. 163, 86-94. doi: 10.1104/pp.113.221788

Schultink, A., Naylor, D., Dama, M., and Pauly, M. (2015). The role of the plant-specific ALTERED XYLOGLUCAN9 protein in Arabidopsis cell wall polysaccharide O-acetylation. Plant Physiol. 167, 1271-1283. doi: 10.1104/pp. 114.256479

Selig, M., Adney, W., Himmel, M., and Decker, S. R. (2009). The impact of cell wall acetylation on corn stover hydrolysis by cellulolytic and xylanolytic enzymes. Cellulose 16, 711-722. doi: 10.1007/s10570-009-9322-0

Sengkhamparn, N., Bakx, E. J., Verhoef, R., Schols, H. A., Sajjaanantakul, T., and Voragen, A. G. J. (2009). Okra pectin contains an unusual substitution of its rhamnosyl residues with acetyl and alpha-linked galactosyl groups. Carbohydr. Res. 344, 1842-1851. doi: 10.1016/j.carres.2008.11.022

Sinclair, S. A., Larue, C., Bonk, L., Khan, A., Castillo-Michel, H., Stein, R. J., et al. (2017). Etiolated seedling development requires repression of photomorphogenesis by a small cell-wall-derived dark signal. Curr. Biol. 27, 3403-3418. doi: 10.1016/j.cub.2017.09.063

Sychantha, D., and Clarke, A. J. (2018). Peptidoglycan modification by the catalytic domain of Streptococcus pneumoniae OatA follows a ping-pong Bi-Bi mechanism of action. Biochemistry 24, 2394-2401. doi: 10.1021/acs.biochem. $8 \mathrm{~b} 00301$

Sychantha, D., Jones, C. S., Little, D. J., Moynihan, P. J., Robinson, H., Galley, N. F., et al. (2017). In vitro characterization of the antivirulence target of Grampositive pathogens, peptidoglycan O-acetyltransferase A (OatA). PLoS Pathog. 13:e1006667. doi: 10.1371/journal.ppat.1006667

Sychantha, D., Little, D. J., Chapman, R. N., Boons, G. J., Robinson, H., Howell, P. L., et al. (2018). PatB1 is an O-acetyltransferase that decorates secondary cell wall polysaccharides. Nat. Chem. Biol. 14, 79-85. doi: 10.1038/nchembio.2509

Teleman, A., Lundqvist, J., Tjerneld, F., Stålbrand, H., and Dahlman, O. (2000). Characterization of acetylated 4-O-methylglucuronoxylan isolated from aspen employing 1H and 13C NMR spectroscopy. Carbohydr. Res. 329, 807-815. doi: 10.1016/S0008-6215(00)00249-4

Urbanowicz, B. R., Pena, M. J., Moniz, H. A., Moremen, K. W., and York, W. S. (2014). Two Arabidopsis proteins synthesize acetylated xylan in vitro. Plant J. 80, 197-206. doi: 10.1111/tpj.12643

Vogel, J., Raab, T., Somerville, C., and Somerville, S. (2004). Mutations in PMR5 result in powdery mildew resistance and altered cell wall composition. Plant $J$. 40, 968-978. doi: 10.1111/j.1365-313X.2004.02264.x

Waters, M. T., Gutjahr, C., Bennett, T., and Nelson, D. C. (2017). Strigolactone signaling and evolution. Annu. Rev. Plant Biol. 68, 291-322. doi: 10.1146/ annurev-arplant-042916-040925

Weadge, J. T., Pfeffer, J. M., and Clarke, A. J. (2005). Identification of a new family of enzymes with potential $O$-acetylpeptidoglycan esterase activity in both Gram-positive and Gram-negative bacteria. BMC Microbiol. 5:49. doi: 10.1186/ 1471-2180-5-49

Xin, Z., and Browse, J. (1998). Eskimo1 mutants of Arabidopsis are constitutively freezing-tolerant. Proc. Natl. Acad. Sci. U.S.A. 95, 7799-7804. doi: 10.1073/pnas. 95.13.7799

Xin, Z., Mandaokar, A., Chen, J., Last, R. L., and Browse, J. (2007). Arabidopsis ESK1 encodes a novel regulator of freezing tolerance. Plant J. 49, 786-799. doi: 10.1111/j.1365-313X.2006.02994.x

Xiong, G., Cheng, K., and Pauly, M. (2013). Xylan O-acetylation impacts xylem development and enzymatic recalcitrance as indicated by the Arabidopsis mutant tbl29. Mol. Plant 6, 1373-1375. doi: 10.1093/mp/ sst014 
Xiong, G. Y., Dama, M., and Pauly, M. (2015). Glucuronic acid moieties on xylan are functionally equivalent to O-acetyl-substituents. Mol. Plant 8, 1119-1121. doi: 10.1016/j.molp.2015.02.013

Yuan, Y., Teng, Q., Zhong, R., Haghighat, M., Richardson, E. A., and Ye, Z. H. (2016a). Mutations of Arabidopsis TBL32 and TBL33 affect xylan acetylation and secondary wall deposition. PLoS One 11:e0146460. doi: 10.1371/journal. pone. 0146460

Yuan, Y., Teng, Q., Zhong, R., and Ye, Z. H. (2016b). Roles of Arabidopsis TBL34 and TBL35 in xylan acetylation and plant growth. Plant Sci. 243, 120-130. doi: 10.1016/j.plantsci.2015.12.007

Yuan, Y., Teng, Q., Zhong, R., and Ye, Z. H. (2016c). TBL3 and TBL31, two Arabidopsis DUF231 domain proteins, are required for 3-O- monoacetylation of xylan. Plant Cell Physiol. 57, 35-45. doi: 10.1093/pcp/pcv172

Yuan, Y., Teng, Q., Zhong, R., and Ye, Z. H. (2013). The Arabidopsis DUF231 domain-containing protein ESK1 mediates 2-O- and 3-O-acetylation of xylosyl residues in xylan. Plant Cell Physiol. 54, 1186-1199. doi: 10.1093/pcp/pct070

Zhang, B., Zhang, L., Li, F., Zhang, D., Liu, X., Wang, H., et al. (2017). Control of secondary cell wall patterning involves xylan deacetylation by a GDSL esterase. Nat. Plants 3:17017. doi: 10.1038/nplants.2017.17

Zhong, R., Cui, D., Dasher, R. L., and Ye, Z. H. (2018a). Biochemical characterization of rice xylan O-acetyltransferases. Planta 247, 1489-1498. doi: $10.1007 / \mathrm{s} 00425-018-2882-1$
Zhong, R., Cui, D., and Ye, Z. H. (2018b). A group of Populus trichocarpa DUF231 proteins exhibit differential $O$-acetyltransferase activities toward xylan. PLoS One 13:e0194532. doi: 10.1371/journal.pone.0194532

Zhong, R., Cui, D., and Ye, Z.-H. (2017). Regiospecific acetylation of xylan is mediated by a group of DUF231-containing O-acetyltransferases. Plant Cell Physiol. 58, 2126-2138. doi: 10.1093/pcp/pcx147

Zhu, X. F., Sun, Y., Zhang, B. C., Mansoori, N., Wan, J. X., Liu, Y., et al. (2014). TRICHOME BIREFRINGENCE-LIKE27 affects aluminum sensitivity by modulating the $O$-acetylation of xyloglucan and aluminum-binding capacity in Arabidopsis. Plant Physiol. 166, 181-189. doi: 10.1104/pp.114. 243808

Conflict of Interest Statement: The authors declare that the research was conducted in the absence of any commercial or financial relationships that could be construed as a potential conflict of interest.

Copyright (0) 2018 Pauly and Ramirez. This is an open-access article distributed under the terms of the Creative Commons Attribution License (CC BY). The use, distribution or reproduction in other forums is permitted, provided the original author(s) and the copyright owner(s) are credited and that the original publication in this journal is cited, in accordance with accepted academic practice. No use, distribution or reproduction is permitted which does not comply with these terms. 